\title{
The Study on Impact of Ujina Irrigation Canal on Malaria Transmission in District Nuh (Erstwhile Mewat), Haryana
}

\author{
Rajendra Thapar', Sukhvir Singh ${ }^{2}$, Purnima Srivastava $^{3}$
}

${ }^{1}$ Research Scholar, Department of Life Science and Applied Sciences, Bhagwant University, Ajmer, Rajasthan, India. ${ }^{2} J$ Joint Director, National Vector Borne Disease Control Programme, Ministry of Health and Family Welfare, Shastri Park, New Delhi, India.

${ }^{3}$ Dean Research, Bhagwant University, Ajmer, Rajasthan, India.

DOI: https://doi.org/10.24321/0019.5138.201926

\section{I $\quad \mathbf{N} \quad \mathbf{F} \quad \mathbf{O}$}

\section{Corresponding Author:}

Rajendra Thapar, Department of Life Science and Applied Sciences, Bhagwant University, Ajmer, Rajasthan, India.

E-mail Id:

rajthapar2010@gmail.com

Orcid Id:

https://orcid.org/0000-0002-5199-1065

How to cite this article:

Thapar R, Singh S, Srivastava P. The Study on Impact of Ujina Irrigation Canal on Malaria Transmission in District Nuh (Erstwhile Mewat), Haryana. J Commun Dis 2019; 51(3): 46-54.

Date of Submission: 2019-07-26

Date of Acceptance: 2019-09-24

\section{$\begin{array}{llllllll}\mathbf{A} & \mathbf{B} & \mathbf{S} & \mathbf{T} & \mathbf{R} & \mathbf{A} & \mathbf{C} & \mathbf{T}\end{array}$}

Man-made ecological transformations have occurred at an unprecedented magnitude over the past 50 years. Prominent among them are water resource development projects which has a significant impact on transmission dynamics of malaria. The link between irrigation system and malaria in District Nuh (Erstwhile Mewat) of the State of Haryana is studied. Larval and adult mosquitoes were collected fortnightly between January 2017 and December 2017 from two irrigated and two non-irrigated (control) villages in the PHC Ujina. Analysis was done to determine relationships of larval/ adult vector densities between irrigated and non- irrigated villages. Malaria incidence was reported to be over six-fold higher in the irrigated villages than the non-irrigated villages. The number of anopheline breeding habitats was 3.6 times higher in the irrigated villages than the non-irrigated villages. Larval and adult anopheline densities were three to four times higher in the irrigated villages than in the non-irrigated villages, respectively, during the study period. Anopheles culicifacies was the predominant species in the study area. Plasmodium vivax and Plasmodium falciparum rate were significantly higher in the irrigated villages than the non-irrigated villages. The study concludes that proper canal water management could reduce vector abundance and malaria transmission in the irrigated villages.

Keywords: An. Culicifacies, An. Stephensi, Malaria, Plasmodium Vivax, Plasmodium Falciparum, Irrigation Scheme

\section{Introduction}

Malaria is one of the most important parasitic infections in humans. Several initiatives from the international health community in the past decade have lead to an estimated drop in malaria associated mortality from around 1 million in 2000 to about 435,000 in 2017 according to the WHO World
Malaria report 2018. ${ }^{1}$ As per the report, approximately $70 \%$ of the world's malaria burden is concentrated in just 11 countries-10 in sub-Saharan Africa and India. These high-burden nations are home to an estimated 151 million cases of malaria and 275,000 deaths. The Global Technical Strategy (GTS) for Malaria 2016-2030 calls for reducing malaria cases and deaths by at least $40 \%$ by 2020 , at least 
$75 \%$ by 2025 and at least $90 \%$ by 2030 . In 2017, of all the 11 highest burden countries globally, African countries reported increases in malaria cases over the previous year, but only India marked progress in reducing its disease burden, registering a 24\% decrease compared to 2016.

Among the current recommended interventions to control the disease is the use of insecticidal nets or indoor residual spraying with insecticide to control vector mosquito populations. A major issue arising from the intense deployment of insecticides is the development of resistance to the chemical agents. ${ }^{2}$ It is a ubiquitous problem, regarded as a major hindrance in the control of malaria. Furthermore, the use of insecticides is not restricted to public health; in fact, around $90 \%$ of insecticides are deployed in agriculture. ${ }^{3}$ Many disease vectors are present in agricultural areas and are therefore likely exposed to insecticides used to control agricultural pests. The intensive use of insecticides in agriculture has caused concern for increased selection pressure for insecticide resistance development in disease vectors. This may have negative implications for vector-borne disease control programme. Although the physical environment provides the primary conditions for the breeding of malaria vectors, the socio-demographic environment particularly related to agriculture and irrigation projects plays a significant role in the incidence of the vector borne disease.

The world's population is predicted to further increase from six billion currently to about 7.4 billion by 2050 and most of the projected global population growth will take place in developing countries that already suffer from food shortages and health problems. ${ }^{4}$ Irrigation has assisted food production in many parts of the world; from the 1960 s to the 1980s irrigated land accounted for more than $50 \%$ of the increase in global food production. ${ }^{5}$ The construction of dams and impoundment of reservoirs has been the principal means for the provision of irrigation water. Irrigation has numerous potential benefits. Most importantly, it may contribute substantially to food security and economic progress, which in turn provides rural households with greater purchasing power for essential commodities, including improved access to health care delivery services and education. ${ }^{6}$

Literature search was done to understand the prevalence or incidence of malaria in relation to irrigation projects. Majority of studies has categorized the predominant epidemiological situations of malaria transmission as Stable and Unstable Malaria. Stable Malaria is characterized by year-round transmission with some seasonal variations. Inhabitants of stable malaria transmission areas have a high natural immunity and epidemics are unlikely events. In contrast, transmission is not sufficient in the dry season to maintain immunity in areas of seasonal or unstable malaria. In these areas there is a high potential for epidemics to occur. The majority of the studies revealed that rice field inhabitants, despite high Anopheles densities throughout the year due to irrigation water, often have lower prevalence rates than people in control villages. This claim was based on the assumption that communities in the area where irrigation was developed were originally ecological replicates of the non-irrigated communities. Immunological as well as socioeconomic factors and control programs strongly influence the parasitological parameters. For example in the Kou valley, Burkina Faso, malaria prevalence rates ranged from $16-58 \%$ in an irrigated village, compared to $35-83 \%$ in a non irrigated village. ${ }^{7}$ Furthermore, in Mali, a two-fold reduction in the annual malaria incidence was observed after the implementation of irrigation, although rice cultivation changed transmission from seasonal to perennial. ${ }^{8}$ It has been observed that in unstable malaria transmission areas, the introduction of irrigation places the non-immune population at a high risk of acquiring the disease. It might alter malaria transmission from seasonal to perennial and malaria endemicity from mesoendemic to hyperendemic, as observed in Rosso, Richard Toll and Podor in the Senegal River Basin ${ }^{9}$ or the Gezira scheme. ${ }^{10}$ A study conducted in a dry coastal area of Peru, found malaria incidence five-fold higher in villages with houses in close proximity to irrigated fields and irrigation canals, compared with villages in the non-irrigated area. ${ }^{11}$ In Sri Lanka, a five-fold higher malaria incidence was reported following the introduction of Mahaweli systems $\mathrm{H}$ and B. ${ }^{12}$ Another study, comparing the malaria prevalence in four villages, two relatively new and two ancient, of which two were irrigated and two non-irrigated, showed prevalence rates of $4.8 \%$ and $2.5 \%$ for irrigated and nonirrigated, respectively. Both the irrigated and non-irrigated new villages had much higher prevalence rates than the old ones, which was explained by changing livelihoods, less knowledge on malaria and fewer personal protection measures in the 15 new villages. ${ }^{13}$

This paper presents findings of an assessment of malaria transmission along Ujina Irrigation Drain passing through the malaria endemic Ujina PHC of District Nuh of Haryana. Entomological studies were carried out in two malaria endemic villages irrigated by the drain and two non-irrigated villages under the PHC. The aim of the assessment was to identify associations between irrigated agriculture and vector borne disease and quantify to these. Disease prevalence, relative impact on agricultural productivity in economic terms and the cost of various malaria-control interventions in practice are discussed. A methodology is proposed that uses in adequate health data in combination with a multispectral approach. 


\section{Material and Methods}

\section{Study Area}

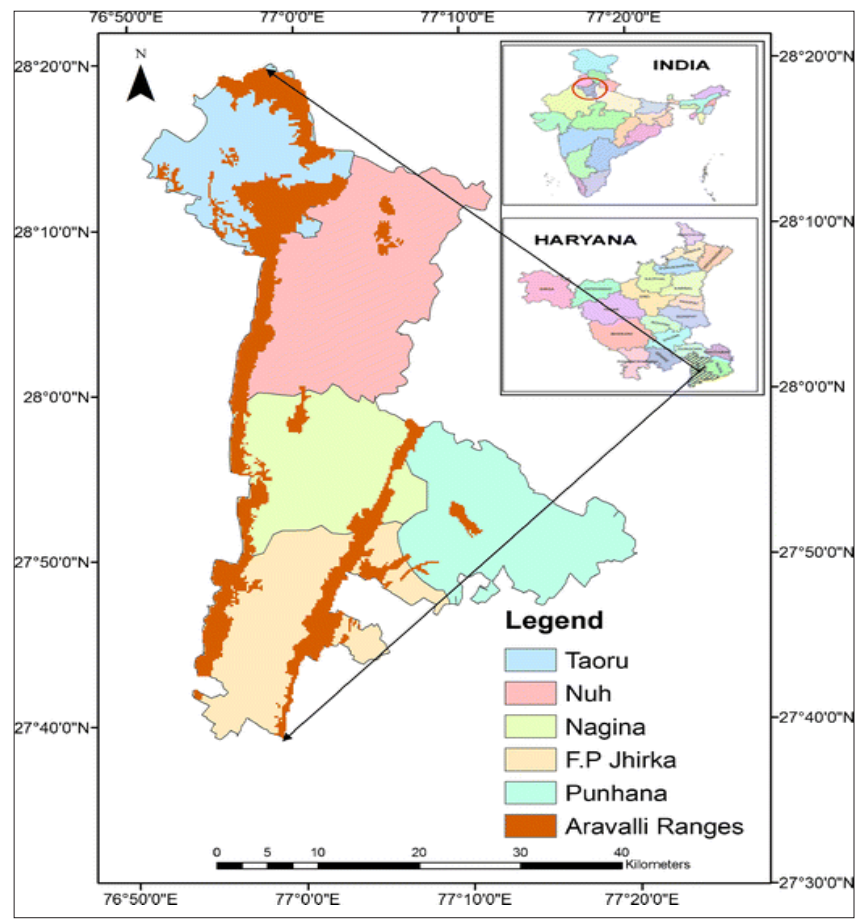

Figure I.Map of District Nuh

District Nuh is one of the 22 districts of Haryana state in northern India. Nuh district lies between $26^{\circ}$ and $30^{\circ}$ North latitude and $76^{\circ}$ and $78^{\circ}$ East longitude adjacent to Gurgaon withan average annual rainfall of $336-440 \mathrm{~mm}$.

Nuh falls under the Sub-Tropical, Semi-arid climatic zone with extremely hot temperature in summer. May and June are the hottest months of the year with the temperature ranging from $30^{\circ} \mathrm{C}$ to $48^{\circ} \mathrm{C}$. January, on the other hand is the coldest month with temperature ranging between $2^{\circ} \mathrm{C}$ to $25^{\circ} \mathrm{C}^{14}$. Mewat district largely comprises of plains. Inconsistency in Mewat's topography is evident from its patches of land with hills and hillock of the Aravali mountains on one hand and plains on the other. The soil of Mewat is light in texture, particularly sandy, sandy loam and clay loam. The upper hills are mostly barren. The annual rainfall varies considerably from year to year. Maximum rainfall is experienced during the monsoon season which reaches its peak in the month of July. The principal precipitation occurs during monsoon period from June to September when about $80 \%$ of the rainfall is received. Since the major outbreak of malaria in Mewat region in 1996, earlier studies carried out enumerating various factors associated with malaria prevalence and persistence in the traditionally known epidemic belt of the north-western plains of India. The ground water in the district area is saline and salinity increases with depth. The district is socio economically backward. Agriculture, the base economic activity of the people is deprived of irrigation. There is no river and area is drained by artificial drains namely Nuh, Ujina \& Kotla drains. These drains carry rain water into Yamuna river. Gurgaon canal carries water to the area which is distributed through Nuh, Firozpur Jhirka, Uttawar, Mandkola, Hathin and Chhyansa distributaries. ${ }^{15}$ Based on the last few years PHC-wise and village-wise epidemiological data, the study was conducted in one of the most malaria endemic PHC namely Ujina which is adjacent to the strategically important Ujina drain (Table 1).

Two irrigated (Jai Singhpur and Naushera) and two nonirrigated (Devla Nagli and Dhakli) villages were selected from PHC Ujina for carrying out the study. The drain irrigated villages, situated within $1 \mathrm{~km}$ radius from the irrigated farms, had a population of around 7,400 in 2016. The nonirrigated (control) villages, with a total population of around 7,500, are located $10-15 \mathrm{~km}$ from the irrigation scheme but with similar agrarian socio-economic standards except irrigation practice. In Mewat, 73\% population resides in kucha house or partially constructed house. The mosquito densities are dependent on availability of suitable larval habitats. In India, An.culicifacies is distributed all over the country and is considered to be the major vector of rural malaria. An.culcifacies is also the major vector in District Nuh contributing to $60-70 \%$ of the malaria incidences in the region. This vector species breeds in ground water collections and the streams of water drainage schemes. During rainy season, breeding places are numerous, hence the vector densities of An.culicifacies is reported at its peak. The other important vectors of malaria are An.minimus and An.fluviatilis. Malaria is the leading public health challenge with an unstable/ seasonal trend, peaking between July to October during and following the major wet season months. Plasmodium vivax is the predominant malaria parasite, causing $70 \%$ of malaria infections, followed by Plasmodium falciparum. In a study carried out during 1989-91 in Gujarat, it was observed that An. culicifacies is most abundant in the villages situated on the bank of rivers (46\%) followed by hilly (23\%), canal irrigated (22\%), coastal (7\%) and non-canal-irrigated areas (2\%). In Orissa, stream and riverside villages had high densities.

\section{Retrospective Clinical Malaria Data Collection}

To assess the impact of irrigation on malaria risk, retrospective monthly laboratory-confirmed malaria data were collected from the Ujina Primary Health Centre during the study period (January 2016 - December 2016) (Table 2). A malaria data set was sorted by village, and type of malaria parasite as confirmed by microscopy. Monthly malaria incidence (cases per 1,000 population per month) was calculated for each village to determine the level of malaria transmission in each village across months of the year. 
Table I.Epidemiological Situation of different PHCs of District Nuh (Mewat) Haryana for the period 2012-16

\begin{tabular}{|c|c|c|c|c|c|c|c|c|c|c|c|c|c|c|c|c|c|}
\hline \multirow{2}{*}{$\begin{array}{l}\text { Sr. } \\
\text { No. }\end{array}$} & \multirow{2}{*}{$\begin{array}{c}\text { Name of } \\
\text { PHC }\end{array}$} & \multirow{2}{*}{$\begin{array}{c}\text { Population } \\
2016\end{array}$} & \multicolumn{3}{|c|}{2012} & \multicolumn{3}{|c|}{2013} & \multicolumn{3}{|c|}{2014} & \multicolumn{3}{|c|}{2015} & \multicolumn{3}{|c|}{2016} \\
\hline & & & PV & PF & Total & PV & PF & Total & PV & PF & Total & PV & PF & Total & PV & PF & Total \\
\hline 1. & Nuh & 160995 & 262 & 3 & 265 & 186 & 7 & 193 & 78 & 0 & 78 & 412 & 12 & 424 & 498 & 4 & 502 \\
\hline 2. & Ujina & 113699 & 585 & 4 & 589 & 268 & 41 & 309 & 76 & 8 & 84 & 1711 & 1008 & 2719 & 2007 & 513 & 2520 \\
\hline 3. & Ghasera & 104244 & 167 & 0 & 167 & 78 & 1 & 79 & 19 & 0 & 19 & 14 & 3 & 17 & 27 & 0 & 27 \\
\hline 4. & Tauru & 151849 & 3 & 1 & 4 & 19 & 3 & 22 & 1 & 0 & 1 & 11 & 4 & 15 & 6 & 0 & 6 \\
\hline 5. & MP Ahir & 67074 & 8 & 0 & 8 & 2 & 0 & 2 & 0 & 0 & 0 & 0 & 0 & 0 & 1 & 0 & 1 \\
\hline 6. & Punhana & 89778 & 4 & 0 & 4 & 11 & 0 & 11 & 7 & 0 & 7 & 1804 & 15 & 1819 & 1178 & 1 & 1179 \\
\hline 7. & Pinan-gwan & 77323 & 159 & 2 & 161 & 252 & 7 & 259 & 50 & 3 & 53 & 928 & 6 & 934 & 300 & 0 & 300 \\
\hline 8. & Tigaon & 105266 & 3 & 0 & 3 & 20 & 1 & 21 & 10 & 0 & 10 & 60 & 1 & 61 & 79 & 0 & 79 \\
\hline 9. & Singar & 106542 & 17 & 0 & 17 & 65 & 0 & 65 & 5 & 0 & 5 & 518 & 6 & 524 & 347 & 3 & 350 \\
\hline 10. & Marora & 88290 & 31 & 1 & 35 & 41 & 11 & 52 & 15 & 6 & 21 & 19 & 4 & 23 & 40 & 0 & 40 \\
\hline 11. & Nagina & 94537 & 17 & 0 & 17 & 38 & 1 & 39 & 16 & 3 & 19 & 41 & 3 & 44 & 32 & 0 & 32 \\
\hline \multirow[t]{3}{*}{12.} & F.P. Jhirka & 113728 & 30 & 0 & 30 & 29 & 0 & 29 & 11 & 0 & 11 & 46 & 5 & 51 & 23 & 1 & 24 \\
\hline & Total & & 1286 & 11 & 1297 & 1009 & 72 & 1081 & 288 & 20 & 308 & 5564 & 1067 & 6631 & 4538 & 522 & 5060 \\
\hline & $\begin{array}{c}\mathrm{Pv} / \mathrm{Pf} \\
\text { percentage }\end{array}$ & & $99.15 \%$ & $0.85 \%$ & & $93.34 \%$ & $6.66 \%$ & & $93.51 \%$ & $6.49 \%$ & & $83.90 \%$ & $16.09 \%$ & & $89.68 \%$ & $10.3 \%$ & \\
\hline
\end{tabular}

Source: District Malaria Office, Nuh

\section{Adult and Larvae Sampling}

Larvae and adult mosquitoes were collected from the irrigated and non-irrigated study villages. Indoor resting mosquitoes were collected from human dwellings and cattlesheds during early morning (0600 to $0800 \mathrm{hrs}$.) in each village using a suction tube and torch light. ${ }^{16}$ The adult collections were made every month during 2017and anophelines collected were morphologically identified to species following standard keys. ${ }^{17-20}$ The average monthly man hour densities of vectors An. culicifacies and An. stephensi were calculated using the formula: Number of mosquitoes of each vector species collected $\times 60 /$ Total collection time in minutes. The dead and alive mosquitoes were brought to thelaboratory for further processing to study various entomological parameters.

ISSN: 0019-5138 DOI: https://doi.org/10.24321/0019.5138.201926 
Table 2.High Risk malaria villages in CHC Nuh, PHC Ujina in district Nuh year 2016

\begin{tabular}{|c|c|c|c|c|c|}
\hline Sr. No. & Name of Village & Total Population & Pv positive & Pf positive & Total positive Malaria Cases \\
\hline 1. & Ranika & 2890 & 271 & 5 & 276 \\
\hline 2. & Islam Bass & 592 & 8 & 1 & 9 \\
\hline 3. & Ujina & 10138 & 103 & 5 & 108 \\
\hline 4. & Bibipur & 3059 & 147 & 47 & 194 \\
\hline 5. & Gund Bas & 1282 & 148 & 5 & 232 \\
\hline 6. & JaiSinghpur & 3621 & 126 & 106 & 153 \\
\hline 7. & Naushera & 3780 & 113 & 40 & 138 \\
\hline 8. & Kairaka & 3847 & 129 & 9 & 39 \\
\hline 9. & DevlaNagli & 5353 & 37 & 2 & 77 \\
\hline 10. & Dhakli & 2190 & 21 & 56 & 137 \\
\hline 11. & Kontlaka & 1343 & 65 & 72 & \\
\hline
\end{tabular}

Perennial and seasonal mosquito breeding habitats were searched in and around the study villages during (i) premonsoon (March to June 2017) (ii) monsoon (July to September 2017) and (iii) post-monsoon season (October to December 2017). All available potential mosquito breeding habitats such as irrigation canals, canal leakage pools (i.e. pools formed from leaking main canals), irrigated field paddies (water-logging in the field due to over-irrigation and poor drainage canals), mud-brick-making pits, rain pools and other man-made pools, such as water-holding wells were surveyed within $1 \mathrm{~km}$ radius of each study village using standard dippers. In non-irrigated villages, mosquito breeding were searched in water storage cemented tanks, underground water storage cemented tanks, cattle troughs, overhead tanks, while the peri-domestic (outdoor) breeding was observed on road side water collections, water tanks with tubewells, agricultural field, sewage pools, rain pools, borrow pits. Because of poor construction and lack of maintenance, most of the irrigation canals were leaking, creating permanent pools at undesirable places. Sometimes, poorly laid out furrows formed waterlogged areas in the field. Each dip was examined carefully and collected larvae were brought to the laboratory for further investigations.

\section{Result}

\section{Mosquito breeding sites and larval density}

During the study period, a total of six types of mosquito breeding habitats (i.e., brick-making pits, rain pools, nonfunctioning canal pools, leakage pools from irrigation canals and agricultural field puddles) were identified (Table 3). While all six types of mosquito-breeding habitats existed in the irrigated villages, only two (brick-making pits and rain pools) were found in the non-irrigated villages. Anopheles culicifacies was the most common species in all study villages. Larvae of this species were predominantly collected from irrigation-associated breeding sites. Anopheles stephensi was the second-most abundant species predominantly occurring in cattle trough, puddles and leakage pools from irrigation canals in irrigated villages. In the non-irrigated villages, An.culicifacies was the dominant species, whose larvae were commonly found in rain pools, followed by An. stephensi. Overall, the irrigation scheme provided considerable breeding habitats for malaria vector mosquitoes.

Table 3.Summary of potential breeding sites of anopheline in irrigated and non-irrigated study villages in the PHC Ujina, District Nuh

\begin{tabular}{|c|c|c|c|c|c|c|}
\hline \multirow{2}{*}{ Type of larval habitat } & \multicolumn{3}{|c|}{ Irrigated villages } & \multicolumn{2}{c|}{ Non-irrigated villages } \\
\cline { 2 - 7 } & $\begin{array}{c}\text { No. } \\
\text { potential } \\
\text { breeding } \\
\text { habitats (\%) }\end{array}$ & $\begin{array}{c}\text { No. } \\
\text { positive } \\
\text { breeding } \\
\text { site (\%) }\end{array}$ & $\begin{array}{c}\text { \% of } \\
\text { positive } \\
\text { breeding } \\
\text { sites }\end{array}$ & $\begin{array}{c}\text { No. } \\
\text { potential } \\
\text { breeding } \\
\text { habitats (\%) }\end{array}$ & $\begin{array}{c}\text { No. } \\
\text { positive } \\
\text { breeding } \\
\text { site (\%) }\end{array}$ & $\begin{array}{c}\text { \% of } \\
\text { positive } \\
\text { breeding } \\
\text { sites }\end{array}$ \\
\hline Cattle troughs/ roadside pits & $20(6.7)$ & $9(5.6)$ & $45.00 \%$ & $56(39.2)$ & $21(46.7)$ & $37.50 \%$ \\
\hline Rain pools & $41(13.8)$ & $20(12.5)$ & $48.80 \%$ & $87(60.8)$ & $24(53.3)$ & $27.60 \%$ \\
\hline Non-functioning canal pools & $22(7.4)$ & $10(6.3)$ & $54.40 \%$ & - & - & - \\
\hline
\end{tabular}




\begin{tabular}{|c|c|c|c|c|c|c|}
\hline Leakage pools from irrigation canals & $55(18.5)$ & $25(15.6)$ & $45.40 \%$ & - & - & - \\
\hline Agricultural field puddles & $160(53.7)$ & $96(60.0)$ & $60.00 \%$ & - & - & - \\
\hline Total & $298(100)$ & $160(100)$ & $53.70 \%$ & $143(100)$ & $45(100)$ & $31.50 \%$ \\
\hline
\end{tabular}

In the non-irrigated villages, during the pre-monsoon season, indoor breeding of An. culicifacies was recorded in underground water storage cemented tanks and larval density ranges from 5 to 16 larvae per dip which was used for the construction work. An. stephensi breeding was observed in cattle troughs and overhead tanks and larval density ranges from 5 to 14 larvae per dip. During monsoon, the numbers of breeding places were increased. During this season indoor breeding of An. culicifacies larvae were found in water storage cemented tanks and larval density ranges from 5 to 11 larvae per dip and in underground water storage cemented tanks the larval density ranges from 7 to 18 larvae per dip, while, the outdoor breeding was noted on road side water collections with larval density ranges from 12 to 27 larvae per dip, water tanks with tubewells the larval density ranges from 8 to 21 larvae per dip, in irrigation channels 13 larvae per dip were observed, in rain pools larval density ranges from 8 to 19 larvae per dip and borrow pits. In the post-monsoon season underground water storage cemented tanks (6-14 larvae per dip), road sidewater collections (8-17 larvae per dip), water tanks with tubewells, were found to be preferred breeding habitats for An. culicifacies.

The number of potential mosquito breeding sites was two times higher in the irrigated villages $(n=298)$ than non-irrigated villages $(n=143)$ during the study period. Of these, $53.7 \%(n=160)$ and $34.5 \%(n=45)$ were found positive for larval anopheline mosquitoes in the irrigated and nonirrigated villages, respectively. Agricultural field paddies and leakage pools from irrigation canals contributed over $75 \%$ of larval anopheline breeding habitats in the irrigated villages while rain pools accounted for over half of the total larval breeding sites in the non-irrigated villages. Overall, there were three to four times more anopheline breeding sites in the irrigated villages than the non-irrigated villages during the study period.

\section{Adult Anopheles Density}

An.culicifacies is distributed all over the country and is considered to be the major vector of rural malaria. An.culcifacies is also the major vector in district Nuh contributing to $60-70 \%$ of the malaria incidences in the region. Other important vectors of malaria are An. stephensi, An.minimus and An.fluviatilis.

A total of 2296 adult anopheles were collected in the study villages (both irrigated and non-irrigated villages) Graph 1. Of these, the majority were collected from the irrigated villages.An. culicifacies was the predominant species in both irrigated and non-irrigated villages followed by $A n$. stephensi. An. culicifacies vector breeds in ground water collections and the streams of water drainage schemes. It has been observed that during rainy season, breeding places are numerous in both irrigated and non-irrigated villages, hence the vector densities of An.culicifacies is reported at its peak. The density of adult anopheles was significantly higher $(P<0.001)$ in the irrigated villages than the non-irrigated villages throughout the study period.

The monthly mosquito density increased remarkably immediately during and after the monsoon, between June and October (Figure 2). Overall, the densities of malaria vector mosquitoes were substantially higher in the irrigated villages than in the non-irrigated villages throughout the study period.

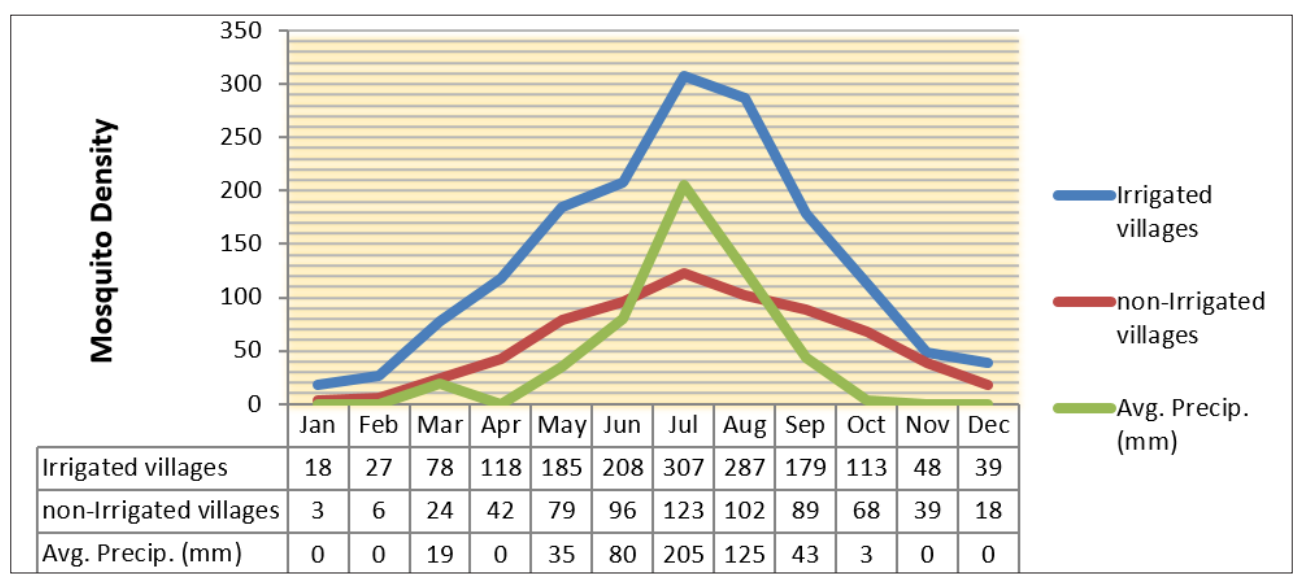

Figure 2.Month-wise mosquito density and average precipitation data in irrigated and nonirrigated villages in PHC Ujina of District Nuh during 2017 


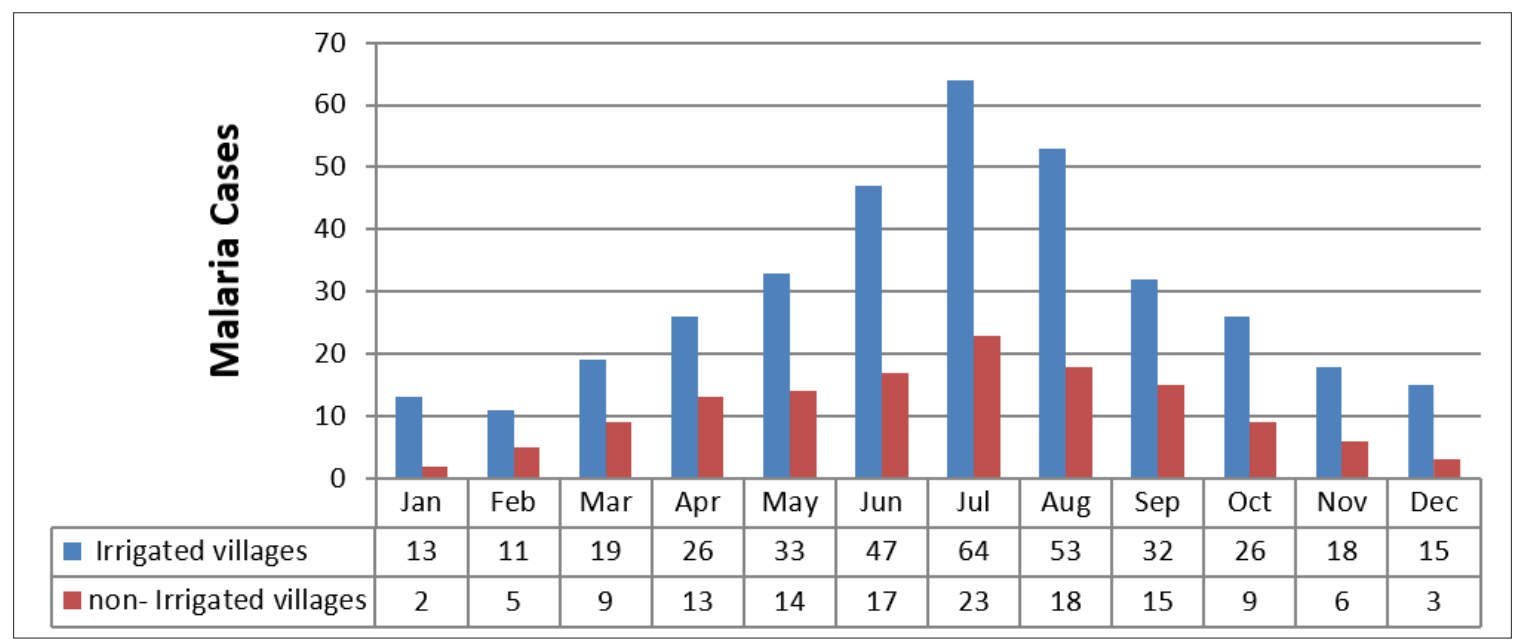

Figure 3.Month-wise malaria cases in irrigated and non-irrigated villages in PHC Ujina of District Nuh during 2017

\section{Malaria Prevalence}

In the study villages, diagnosis of malaria cases was done using the Rapid Diagnostic Test (RDT) kits during the rainy season (June/ August 2017) and the post rainy season (September/ October 2017). Malaria microscopy, which is a time-tested "Gold Standard" test, was also performed in certain cases for malaria diagnosis to further confirm the malaria. The slides with thick and thin blood smears were prepared, properly labelled, air dried and examined under microscope in laboratory. The monthly malaria incidence was significantly higher in the irrigated villages compared to the non-irrigated villages (Figure 3). The data showed that, in the irrigated villages, malaria transmission was observed throughout the year with peak observed between May and September. Malaria transmission occurred across all months of the year in the irrigated villages, unlike the nonirrigated villages where transmission occurred mainly during the monsoon and post-monsoon months (July to August) with few cases in the dry season. Overall, monthly malaria incidence was over three-fold higher in the irrigated villages than the non-irrigated villages during the study period.

\section{Discussion}

District Nuh of Haryana is long known for malnutrition and ensuring food security to the huge population is big challenge. Alarmed by these challenges, several largeand small-scale irrigation schemes are under construction across the region with the goal of ensuring food security and alleviating poverty. However, the negative impact of these emerging irrigation schemes on vector-borne disease, especially malaria - a disease that that affects mainly the rural poor population. Development of irrigation schemes in sub-Saharan Africa has been blamed for the increase of malaria risk through creating favourable breeding sites for malaria vector mosquitoes. ${ }^{21,22}$

The present study indicated that the irrigation schemes of
District Nuh crossing the PHC Ujina resulted in increased malaria transmission in communities living in the irrigated villages throughout the year. Irrigation-associated mosquito breeding habitats (irrigated field puddles, leakages fromirrigation canals and non-functional canal pools) were the prominent malaria vector breeding sites throughout the year. The high vector density of major malaria vectors An. culicifacies and An. stephensi in irrigated villages coupled with their high potential to inoculate the predominant malaria parasite Plasmodium vivax and Plasmodium falciparum, confirms the significant risk of high malaria transmission in the communities living close to irrigation schemes. The availability of water for mosquito breeding, the irrigation schemes appear to extend the malaria transmission into the post-monsoon season in the irrigated villages.

The study confirmed that post monsoon malaria transmission was established in the irrigated villages adjoining the irrigational canal. In tropical Africa, where seasonality in rainfall drives the seasonal dynamics of malaria transmission, the presence of irrigation activities has been shown to have a dampening effect on the seasonality of malaria transmission. ${ }^{23} \mathrm{~A}$ previous study indicated that fluctuation of malaria incidences are highly influenced with the climatic factors. ${ }^{24}$ The climate variability impacts the incubation rate of Plasmodium parasites and breeding activities of Anopheles is considered as an important environmental contribution to malaria transmission dynamics. ${ }^{25,26}$ However, the present study confirmed that the irrigation canal system in the PHC Ujina have created conducive conditions for mosquito breeding during the dry season and thus the period of malaria transmission is extending throughout most of the year. Significantly higher larval anopheline densities observed in the irrigated villages than in the non-irrigated villages throughout the study period confirms that irrigation drives mosquito abundance. 
The introduction of irrigation with a network of canals and dams or the extension of wet periods for continuous rice cultivation establishes new aquatic environments. ${ }^{27}$ Furthermore, the longevity of the mosquito is enhanced because of greater humidity during irrigation..$^{28}$ In principle, rice fields may be habitable by different species of mosquito throughout all stages of plant growth. ${ }^{29}$ Mosquito densities usually decrease as the plants develop, because mosquitoes have reduced access to the water for ovi-position. ${ }^{30}$ In general, water depth, duration of flooding, temperature, crop growth rates and the area of the rice field determine vector productivity. Furthermore, malaria transmission is greatly influenced by environmental and climatic factors, because vectorial capacity is strongly driven by humidity, rainfall, and temperature.

Strong positive correlation between canal water irrigation and anopheline larval density coupled with the presence of leakage pools from irrigating canals and water-logged field puddles in the irrigated villages indicate improper canal water management that led to increased malaria vector breeding and thus intensified malaria transmission.This is due to the thriving of the most common malaria vector species An. culicifacies in irrigated fields and seepages created by the irrigation schemes.

\section{Conclusion}

This study revealed that poor canal water management of Ujina irrigation canal led to a proliferation of malaria vector mosquito breeding sites and intensified malaria transmission in the irrigated villages in PHC Ujina, district Nuh, Haryana. Proper canal water management, avoiding unnecessary water logging in the field during the months of peak malaria transmission could reduce vector abundance and malaria transmission in the irrigated villages. A clear understanding of vector density pattern, their seasonal prevalence and resting behaviour helps to plan appropriate and timely vector control measures. In our study area, An. culicifacies, An. stephensi were the main vectors prevalent during all the seasons. The artificial ponds and seepage pools of canal are the major breeding sites for An. culicifacies. Thus, in the canal command area, control of malaria transmission requires indoor residual spraying along with insecticide-treated bednets, use of larvicides in seepage pools and introduction of larvivorous fish in artificial ponds.

Moreover, community awareness is needed to encourage irrigators to use personal protections for malaria prevention. The finding that the malaria incidence is associated with adult vector abundance and vector abundance is correlated with larval abundance, which is affected by canal water releases and irrigation in nearby fields, reaffirms the importance of proper canal water management on malaria transmission. Proper water management and canal maintenance for source reduction through environmental management could help to reduce mosquito-breeding sites and thus malaria transmission. Field experimental studies are needed to further assess how manipulating canal water release could reduce larval and adult vector abundance and hence lower the risk of malaria transmission.

\section{Conflict of Interest: None}

\section{References}

1. WHO: World Malaria Report: 2018. World Health Organization. 2018, 1-210. (https://www.who.int/ malaria/publications/world-malaria-report-2018/en/)

2. Nauen R. Insecticide resistance in disease vectors of public health importance. Pest ManagSci 2007; 63: 628-633. 10.1002/ps.1406.

3. Labbé $P$, Alout $H$, Djogbénou L, Pasteur $N$ et al. Evolution of Resistance to Insecticide in Disease Vectors 2011, Massachusetts, USA: Elsevier.

4. United Nation's World Urbanization Prospects. The 2014 Revision. United Nations Department of Economic and Social Affairs/Population Division, New York (https://www.un.org/en/development/ desa/publications/2014-revision-world-urbanizationprospects.html).

5. World Bank \& United Nations Development Programme Irrigation and Drainage Research: A Proposal. 1990,The World Bank, Washington, D.C. (http://hdr.undp. org/sites/default/files/reports/219/hdr_1990_en_ complete_nostats.pdf).

6. Keiser J, De Castro MC, Maltese MF et al. Effect of irrigation and large dams on the burden of malaria on a global and regional scale. American Journal of Tropical Medicine and Hygiene 2005; 72(4): 392-406.

7. Boudin C, Robert V, Carnevale P et al. Epidemiology of Plasmodium falciparum in a rice field and a savanna area in Burkina Faso. Comparative study on the acquired immune-protection in native populations. Acta Trop 1992; 51(2): 103-111.

8. Sissoko MS, Dicko A, Briet OJ et al. Malaria incidence in relation to rice cultivation in the irrigated Sahel of Mali. Acta Trop 2004: 89(2): 161-170.

9. Jobin WR, Diop M. Senegal River Basin Health Master Plan Study. Water and Sanitation for Health Project (WASH). 1994 USAID.

10. Gaddal AA, Haridi AA, Hassan FT et al. Malaria control in the GeziraManagil Irrigated Scheme of the Sudan. $J$ Trop Med Hyg 1985; 88(2): 153-159.

11. Guthmann JP, Llanos-Cuentas A, Palacios A et al. Environmental factors as determinants of malaria risk. A descriptive study on the northern coast of Peru. Trop Med Int Health 2002: 7(6): 518-525.

12. International Irrigation Management Institute. Proceedings of the workshop on Irrigation and vector 
borne disease transmission. IIMI Pub, Colombo. 1986

13. Dixon RA, Pinikhana JP. Malaria and proximity to irrigation projects: a parasitaemia prevalence study from Sri Lanka. Mosquito Borne Disease Bulletin 1994; 11: 116-121.

14. Mewat Development Agency (MDA) (2014). Profile of District Mewat. Retrieved from http://mda.nic.in/ Mewat-Profile.htm.

15. Ground water information booklet, Mewat District. Central Ground Water Board Ministry of Water Resource, North Western Region Chandigarh 2012; 1-22.

16. Manual on Practical Entomology in Malaria. Pt II. Methods and techniques. Geneva: World Health Organization 1975; 141-147.

17. Christopher SR. The Fauna of British India, including Ceylon and Burma, Diptera. New Delhi: Today and Tomorrow's Printers and Publishers 1933; 1-359.

18. Nagpal BN, Sharma VP. Indian Anophelines. New Delhi: Oxford IBH 1995; 1-416.

19. Wattal BL, Kalara NL. Region-wise pictorial keys to the female Indian Anopheles. Bull Nat/Soclnd Mal Mosq Dis 1961, 9: 85-138.

20. Das BP, Rajagopalan R, Akiyana J. Pictorial key to the species of Indian Anophelinemosquitoes. Pure and Appli Zoo 1990; 2(3): 131-162.

21. Boelee E, Konradsen F, vanderHoek W (Eds): Malaria in irrigated agriculture: papers and abstracts for the SIMA special seminar at the ICID 18th International congress on irrigation and drainage, Montreal. Colombo: International Water Management Institute; IWMI Working Paper 47; 2002.

22. Ghebreyesus TA, Haile M, Witten KH et al. Incidence of malaria among children living near dams in northern Ethiopia: community based incidence survey. BMJ 1999; 319: 663-666.

23. Mabaso ML, Craig M, Ross $A$ et al. Environmental predictors of the seasonality of malaria transmission in Africa: the challenge. Am J Trop Med Hyg 2007; 76(1): 33-38.

24. Epstein PR. Climate change and human health. $N$ Engl J Med 2005; 353: 1433-1436.

25. Abeku T, Dexlas SJ, Borsboom GJ. Effect of meteorological factors on epidemic malaria in Ethiopia: a statistical modeling approach based on theoretical reasoning. Parasitol 2004; 128(6): 85-96.

26. Bhattacharya S, Sharma C, Dhiman RC et al. Climate change and malaria in India. Current Science 2006; 90: 369-375.

27. Bang YH. Vector-borne diseases associated with rice cultivation and their control in Southeast Asia. International Rice Research Institute Manila, Philippines 1988: 93-99.
28. Service MW. The importance of ecological studies on malaria vectors. Bull Soc Vector Ecol 1989; 14: 26-38.

29. Lacey LA, Lacey CM. The medical importance of riceland mosquitoes and their control using alternatives to chemical insecticides. J Am Mosq Control Assoc 1990; 6(Suppl): 1-93.

30. Rajendran R, Reuben R, Purushothaman S et al. Prospects and problems of intermittent irrigation for control of vector breeding in rice fields in southernIndia. Ann Trop Med Parasitol 1995; 89(5): 541-549. 